\title{
Is it good to share? A case study of the FON and Meraki approaches to broadband provision
}

Article · June 2008

CITATIONS

11

2 authors, including:

\section{Catherine Middleton}

Ryerson University

259 PUBLICATIONS 489 CITATIONS

SEE PROFILE
READS

12 


\title{
Is it Good to Share? A Case Study of FON and Meraki Approaches to Broadband Provision
}

\author{
Authors: Catherine Middleton, Canada Research Chair, Ryerson University, Toronto, Canada, \\ catherine.middleton@ryerson.ca \\ Amelia Bryne Potter, Community Wireless Infrastructure Research Project, \\ ameliabpotter@gmail.com
}

Paper presented to the International Telecommunications Society 17th Biennial Conference Montreal, June 2008

\begin{abstract}
This paper provides a detailed assessment of FON and Meraki approaches to extending broadband infrastructures by sharing connections within communities. The paper outlines elements of good broadband infrastructure, and considers the extent to which each approach is able to deliver good service to its users. Both approaches have had some success, but the Meraki approach appears to be more feasible. Neither approach is able to build highly robust broadband infrastructure. It is concluded that community-led initiatives to develop large scale infrastructures, while promising in some respects, face many challenges.
\end{abstract}

\section{Introduction}

This paper investigates the idea of extending the availability of broadband networks by providing shared access to existing connections. The objective of the paper is to understand whether such projects offer viable methods for developing and delivering broadband infrastructure, infrastructure that meets the needs of the public. The paper considers the approaches taken by two companies, FON (www.fon.com) and Meraki (meraki.com). Both promote the idea that individuals can share their internet connections to provide other members of their communities with increased broadband access.

FON was started in Spain in late 2005 by Argentinean entrepreneur Martin Varsavsky, and bills itself as the 'Wi-Fi revolution.' Its basic premise is that by sharing their internet connections at home, people can have access to other people's internet connections elsewhere in the world. FON makes it easy for individuals to set up secure Wi-Fi hotspots. These hotspots are free for FON community members (called 'Foneros') and open to anyone willing to pay a fee for 
connectivity.

Meraki sells hardware to create wireless mesh networks. Like FON, the idea is that an individual can share an internet connection with others, but the technology is different. Meraki's approach assumes that individuals want connectivity inside their homes, so rather than developing hotspots that provide access points outside homes, the Meraki routers are designed to connect neighbours and neighbourhoods, providing good quality connections inside homes. Meraki networks are planned to cover specific areas, and the person (or group) planning the network determines pricing for network access. Frequently, these networks are used to provide very low cost or free bandwidth to low income communities.

The paper provides a detailed description of each company's approach to developing broadband infrastructure, explains the business models of the two companies, and considers the practicalities of their approaches to broadband provision. In a context where efforts to provide increased broadband access should be welcome, it is still important to understand whether such efforts actually result in beneficial outcomes for users. The paper concludes that neither approach is likely to result in the development of sustainable infrastructure that can provide high quality, reliable service to users. Despite this conclusion, there is value in both approaches, and Meraki's networks in particular are likely to have a positive impact on the overall accessibility of broadband networks.

\section{Motivation for the Research}

For the past few years, wireless local area networks (WLANs) have been viewed as effective means of extending the reach of broadband infrastructures (Bina \& Giaglis, 2005; International Telecommunication Union, 2004). Affordable and relatively easy to deploy, Wi-Fi networks (which operate using 802.11 standards over license exempt or unlicensed frequency bands) offer the promise of ubiquitous broadband internet access in public spaces. Tens of thousands of Wi-Fi hotspots have been deployed around the world by commercial operators (Damsgaard, Parikh, \& Rao, 2006). Community groups like NYCWireless in New York, CuWIN in ChampaignUrbana, Illinois, and Île Sans Fil in Montreal, Québec (among others) have developed wireless networks whose hotspots support the development of vibrant local communities (Crow \& Miller, 2008; Forlano, 2008; Powell \& Shade, 2006). Municipalities like St. Cloud, Florida (Fleishman, 2006), Chaska, Minnesota (Tropos Networks, 2007) and Fredericton, New Brunswick (Powell, 2008) have built Wi-Fi networks that are widely used, providing affordable or free broadband 
access to local residents and visitors. Given the prevalence of these sorts of efforts, supplemented by the enthusiasm for municipal wireless developments in the US (Tapia, Maitland, \& Stone, 2006), it was thought to be "only a matter of time before ubiquitous voice and broadband access services based on public Wi-Fi emerge[d] in town and city centres across Europe" (Francis, Elnegaard, Eskedal, \& Venturin, 2006, p. 1), and presumably elsewhere.

Yet two years later, in mid-2008, the promise of widely available public Wi-Fi has not been realized. Although there are some notable exceptions, ${ }^{1}$ public Wi-Fi has not been deployed on the scale that was predicted, and nor has it been particularly effective in increasing the overall accessibility of broadband networks. Ubiquitous voice and broadband services are certainly not available on any universal sort of basis. The availability of public Wi-Fi now seems to be declining rather than growing. Since August 2007, when Earthlink first signaled its intentions to scale back its involvement in the municipal wireless network sector in the US, many Wi-Fi projects have been cancelled in the planning stages (including networks proposed for the cities of Houston and San Francisco) and networks that were providing connectivity to thousands of users, including MetroFi's networks in Portland, OR, and the Silicon Valley ${ }^{2}$ are being switched off (Cox, 2008; Kim, 2008a). Earthlink has given notice that it will terminate connectivity for Wireless Philadelphia, a network that has been helping to bridge the digital divide in Philadelphia, forcing users to revert to dial-up internet access (Goldman, 2008). Commercial hotspot providers have consolidated their offerings (Tanner, 2008), and alternative technologies like 3G (which provide affordable broadband connections over cellular networks ${ }^{3}$ ) have reduced users' reliance upon hotspot connections.

Despite the decline in wireless infrastructure projects, the demand for solutions to provide individuals with better broadband connections has not decreased. In the US in particular, there is ongoing concern about the lack of a national policy for broadband connectivity (Atkinson, 2007; Bleha, 2005). While Hultell et al. (2007) argue that "Providing affordable wireless access

${ }^{1}$ See for instance the Wireless Leiden project covering the Leiden and surrounding communities in the Netherlands (www.wirelessleiden.nl/english), and the SparkNet-OpenSpark project in Turku, Finland (Stanoevska-Slabeva \& Hongisto, 2006; Tallberg, 2006), open.sparknet.fi. Danigelis (2008) provides a list of community wireless developers' favourite Wi-Fi cities.

${ }^{2}$ See Hudson (2006) for an assessment of the San Francisco and Silicon Valley projects.

${ }^{3}$ Mobile $3 \mathrm{G}$ broadband is available from many providers, including Telstra in Australia, Sprint in the US and 3 and Vodaphone internationally. The service is very simple to use, providing higher speeds than most Wi-Fi networks, in any location that has mobile phone coverage. 
for all user-needs is one of the remaining great challenges for the telecommunications industry" (p. 1), others believe that provision of broadband infrastructure guided by market forces alone does not produce solutions that meet citizens' needs (e.g. Breitbart, Lakshmipathy, \& Meinrath, 2007). It is in this context that projects that offer simple ways to extend existing broadband infrastructure are considered promising, and as is discussed below, there is much optimism about what can be achieved.

The projects of interest in this paper promote the development of broadband infrastructures through the coordinated actions of individuals or local community groups, rather than by governments or business (see Markendahl \& Mäkitalo, 2007, and Välimäki, 2006, for an overview of different types of organizations that have been involved in developing wireless broadband services). This purpose of this paper is to assess the extent to which the 'citizen-led' approaches taken by FON and Meraki can be successful in improving the availability of good public broadband infrastructure. In particular, the paper considers the advantages and disadvantages of each approach, assessed with reference to a list of desirable attributes for good broadband infrastructure (Potter \& Clement, 2007).

The paper begins with a review of relevant literature, highlighting the potential benefits of using $\mathrm{Wi}-\mathrm{Fi}$ to extend the reach of broadband networks. The paper then describes characteristics of good public broadband networks, outlining the criteria that are used to assess the FON and Meraki projects. A general description of each project follows, and the two cases are then compared on the basis of their ability to provide good public broadband infrastructure to their users.

\section{Background and Literature Review}

Bina and Giaglis (2005) provide a good overview of early research on wireless networks, noting that public wireless networks are generally provided by commercial interests or by community groups. There is a growing literature on community-centric approaches to developing wireless networks (see for example a recent special issue of the Journal of Community Informatics on wireless networking, Powell \& Meinrath, 2008). Although grounded in community approaches to wireless networking, this paper does not offer a review of the community wireless movement per se, instead, it focuses on discussion in the literature of the benefits of using wireless technologies to share internet connections.

Francis et al. (2006) make a case for what they call "Open Broadband Access Networks," 
networks that "exploit surplus local loop capacity for public use" (p. 1). Their argument is one of efficiency. Noting that average households make use of less than $2 \%$ of the capacity of their wired broadband connections, they suggest that making surplus bandwidth available to the public through wireless access points is a way to get greater returns on investment in wired broadband infrastructure. In addition, this approach would create a wireless network to supplement (or perhaps compete with) existing cellular network infrastructure. This approach would likely be driven by existing internet access and service providers, but others see opportunities for more community-centric approaches.

Markendahl and Mäkitalo (2007b) also note the potential efficiencies to be gained by sharing existing infrastructure, and identify various types of stakeholders (e.g. hotels, café owners, transportation companies, individuals) that could be involved in providing expanded network access. Of interest here is the idea of 'co-operating private networks,' where various individuals or small private networks collaborate by using some sort of coordinating agency to allow mutual access to each other's networks. It is suggested that the main driver for this approach is "the idea of cheap or free [wireless internet] access [for] everybody without a traditional operator" (p. 4). Damsgaard and colleagues call this approach a 'wireless commons' (Damsgaard et al., 2006), explaining how it is possible for individuals to cooperate to optimize outcomes for all participants. While it is difficult to remove network operators from the picture entirely (after all, they are providing the bandwidth that is being shared), Ohira and colleagues (2007) believe that there is increased interest in offering access to the public over individuals' own personal networks. Bina and Giaglis (2006) also emphasize the fact that community-based wireless projects provide an alternative to commercial infrastructures. Manshaei et al. (2008) demonstrate that the availability of a dense network of community-operated hotspots would reduce the fees for Wi-Fi connectivity charged by a cellular carrier in that area. Arguing that outdoor Wi-Fi coverage is needed, Thompson and colleagues (2007) suggest that it can be provided at low cost, and on a global scale, through sharing of private broadband networks.

Ohira et al. (2007) suggest that sharing is motivated either by the hope of making money, or in the spirit of cooperation. As Tallberg (2006) notes, individuals who participate in peer-topeer hotspot sharing can "gain substantially by getting access to other individuals' WLAN access points and [are] able to get connected to broadband Internet services widely" (p. 5). While sharing is an appealing concept, Wong and Clement (2007) report that most individuals they surveyed were more interested in getting access to others' networks than in sharing their own 
connections. This free-riding behaviour is also identified by Bina and Giaglis (2006). Damsgaard et al. (2006) outline the possible ways in which users' online behaviours can reduce the quality of the shared networks (using a tragedy of the commons argument), but note that if many people are willing to share their network connectivity, "there is potential for a comprehensive and robust infrastructure" (p. 106). For those who do share, Markendahl and Mäkitalo (2007b) emphasize that such initiatives can benefit users by providing them with the bandwidth of fixed broadband networks combined with the availability of cellular networks.

Efstathiou and his colleagues (Efstathiou et al., 2006a; Efstathiou et al., 2006b) believe that the most prevalent application on networks developed using shared wireless infrastructure would be voice over IP (VoIP) telephony, providing free telephone calls for Wi-Fi phone users, in direct competition with the existing cellular networks. Arjona et al. (2007) also point out the disruptive potential of wireless networks, with mesh networks being particularly well-suited to provide an alternative to cellular coverage. Hüsig et al. (2005) argue however that wireless networks are not likely to prove disruptive to mobile network operators, and to date VoIP on Wi-Fi networks has not threatened the dominance of mobile network operators.

Overall, the literature suggests that sharing is both useful and viable, and that the power of communities could be used to build broadband infrastructures that parallel existing networks and offer alternative approaches to infrastructure provision. In addition to observations about the value of sharing wireless network connections, the literature also describes various technical approaches to make such sharing more feasible. Although many people leave their hotspots 'open' to the public (i.e. unencrypted), and allow others (perhaps unintentionally) to use their connections without any sort of login or authentication process (Shah \& Sandvig, 2005), Forsberg (2007) argues that in order for community-based broadband sharing schemes to work, it is essential to be able to authenticate and authorize potential users. Accounting schemes may also be necessary, and all these processes should be cheap and non-intrusive for users. Various approaches for authentication and establishment of trust are outlined by Forsberg (2007), Efstathiou et al. (2006b), Thompson et al. (2007) and Ohira et al. (2007). Välimäki (2006) offers the concept of 'access brokers,' enabling single authentication processes for users on multiple networks, thus encouraging seamless movement across networks and increasing the value of participating in a sharing scheme.

FON and Meraki are among the better known projects already working to develop shared broadband infrastructures, but they are not the only ones. Both FON and Meraki have 
developed specific hardware for use in sharing broadband. Open source software programs like 'NoCatAuth' ${ }^{4}$ (Sandvig, 2004), and 'wifidog,' ${ }^{5}$ developed by the Montreal-based community wireless network Île Sans Fil (Crow \& Miller, 2008), are available to manage user authentication for multiple wireless hotspots. Other groups (e.g. CUWIN, freifunk, Open Mesh ${ }^{6}$ ) have focused on developing open source software that enables meshing (e.g. CUWiNware, DD-WRT and OpenWRT $^{7}$ ). Whisher ${ }^{8}$ offers software for sharing Wi-Fi on a reciprocal basis. Wireless Nomad ${ }^{9}$ and Speakeasy ${ }^{10}$ also facilitate sharing of network connections within neighbourhoods.

No doubt there are many other projects around the world using Wi-Fi to share broadband networks. The two projects of interest here, FON and Meraki, are quite well-known, and have received a lot of attention in the press. They are similar in that they have a common objective of developing community-centric alternatives to existing broadband infrastructure, but their approaches are different. Both are for-profit companies. FON sells equipment to individuals to allow them to create hotspots on their premises, and then provides an infrastructure to aggregate information on hotspot locations, and to manage authentication and billing for hotspot use. Their objective is to facilitate the creation of many hotspots in many locations, so that their members can use this network of hotspots while roaming the world. As these hotspots are provided at individuals' homes, most of them are accessible from outside only. Meraki does not operate networks (except Free the Net in San Francisco, discussed below), instead it sells equipment to individuals and communities to allow them to create shared broadband infrastructures using a mesh network approach. The mesh network is selfconfiguring, easily extended, and designed to provide connectivity inside homes. Meraki is making no effort to develop ubiquitous internet networks, or to facilitate roaming access. Its focus is on developing hardware and software that communities can use to make broadband networks more accessible and more affordable. In the section below, desirable characteristics of

\footnotetext{
${ }^{4}$ nocat.net

${ }^{5}$ dev.wifidog.org/wiki/FAQ

${ }^{6}$ www.open-mesh.com, wiki.freifunk.net/Google_Summer_of_Code_2008_-_Application, www.cuwin.net/about

${ }^{7}$ www.cuwin.net/research, www.dd-wrt.com, openwrt.org

${ }^{8}$ www.whisher.com/about_us.php

${ }^{9}$ www.wirelessnomad.com

${ }^{10}$ www.speakeasy.net/netshare
} 
good public broadband infrastructure are described. This is followed by detailed descriptions of FON and Meraki's approaches to network provision.

\section{Analytical Approach}

Drawing on earlier work done by the Community Wireless Infrastructure Research Project (Middleton, Longford, Clement, Potter, \& Crow, 2006; Potter \& Clement, 2007), this paper assesses the feasibility of the FON and Meraki approaches as means of developing good broadband infrastructure, that is broadband infrastructure that serves the needs of the public. Specifically, we consider whether these infrastructures will benefit users when assessed in terms of usability, usefulness, reliability, quality, sustainability, ubiquity, security, and affordability. ${ }^{11}$ Each of these assessment criteria is described briefly below.

Usability considers the extent to which the deployed network is convenient and easy to use. For instance, does it provide service to a desirable, comfortable location? Can the service be used at any time of day or night? Is it easy to find the network? Is the connection process obvious and simple? Does the location of the connection allow the potential user a wide choice of access devices? Are there any restrictions as to the use of the network?

Usefulness is assessed in terms of whether being able to access the network, as it is deployed, provides value for the user. Is the network available in a location where the user would need connectivity, for instance?

Reliability and quality can be considered together. Is the network always available? Is the speed predictable and constant? Is the speed adequate for the desired use of the network? Is the quality sufficient to carry out desired activities (e.g. making telephone calls, streaming video, uploading or downloading photos)?

Sustainability of the network is also important. Is the connection that is provided likely to be available in the future? Can the network be considered as fairly permanent infrastructure, or is it transitory in nature?

Proponents of community-led wireless initiatives suggest that it is possible to create infrastructure that parallels the existing cellular telephony network. In order to do this, network ubiquity is essential. While ubiquity may have geographic bounds (e.g. coverage within a

\footnotetext{
${ }^{11}$ The Community Wireless Infrastructure Research Project's 'desiderata' for good broadband infrastructure includes additional items, but this list addresses key issues in the development of shared wireless infrastructures.
} 
suburb or city as opposed to coverage of a region), the question of interest here is whether the network is available to its users wherever they would like to use it. Ubiquity is essential to support nomadic use, or roaming. It is noted however that supporting full mobility (e.g. handing off telephone calls from access point to access point) is complex, and likely beyond the capacity of most Wi-Fi network infrastructures.

Security is an important concern for people sharing network connections. Do people who provide network connections have assurance that their networks are safe from intruders? Is the person using the shared network trustworthy, and known to the network? Does the person using the network have assurance that the network is operated by a trusted source?

Finally, good public broadband infrastructure must be affordable. While affordability is measured by individuals based on their overall incomes, the issue here is whether users are likely to be able to manage the cost of connecting to the network as part of their household expenditures.

In the section that follows, the FON and Meraki approaches to providing wireless broadband infrastructure are described. These factual descriptions are followed by a critical assessment of the strengths and weaknesses of each approach, using the criteria outlined above to determine the extent to which each project is able to encourage the development of broadband infrastructure that is in the public interest.

\section{Case Studies}

The information presented below is drawn from a wide variety of sources, including published descriptions of FON and Meraki projects, blogs written by people involved in both projects, interviews with community wireless experts and FON users, postings to the FON and Meraki web forums, and tests of FON hotspots. The authors have not had experience in using a Meraki network. In addition, it is noted that the FON community is multilingual, but the data presented here are based primarily on analysis of the experiences of English language 'Foneros.' The context for the paper is the provision of broadband networks in the developed world, it does not address the possibilities for sharing internet connections in the developing world (where Meraki is establishing a presence).

\section{FON}

FON was founded by Argentinean entrepreneur Martin Varsavsky, in an effort to build a 
mobile internet. Disappointed by the slow rollout of 3G mobile infrastructure, Varsavsky describes FON as a fight for a better internet, deployed by Wi-Fi, on a person by person basis (Simon, 2005). Varsavsky's "WiFi revolution" was officially launched in Madrid, Spain, in February 2006, but was first announced in his blog in November $2005^{12}$. Within 10 days of the unofficial launch, FON hotspots were operational in 18 countries.

The FON 'movement,' as Varsavsky christened it, allows individuals who are willing to share their personal broadband connections free use of the broadband connections of other 'Foneros' around the world. As the movement grows, Varsavsky envisions a world where FON enables ubiquitous and universal Wi-Fi. His concept is simple. FON acts as an aggregator, offering a brand and identity for Wi-Fi hotspots provided by individuals. As more individuals join FON, more connectivity is available for all Foneros.

Initially, FON provided a free open source software program that could be used to convert a widely available Linksys router into a FON hotspot. In September 2006, FON started selling its own customized router, called 'La Fonera,' to provide individuals with a much easier way to create a FON hotspot using their broadband connection. More recently, it released 'La Fonera+,' a router with an ethernet port and updated software. To create a hotspot, a person simply connects a FON router to a broadband connection, and sets up a FON user account. FON also sells 'La Fontenna,' an antenna that boosts the strength of the hotspot signal. A FON hotspot broadcasts two secure signals. ${ }^{13}$ One is a private signal, for use by the hotspot owner. The other is a public signal, for use by Foneros, who sign in to the hotspot with their username and password. The hotspot owner can decide how much bandwidth to allocate to the public signal.

FON began with three types of Foneros. 'Linuses' shared their bandwidth, and could use anyone's FON hotspot for free. "We wanna milk our connection" was the way FON marketed their concept to 'Bills.' Bills were those who wanted to make money, by charging the third type of Foneros, the 'Aliens' for use of their hotspots. Aliens are users who don't have their own FON hotspot, but are willing to pay for use of a FON hotspot. In mid-2007, Varsavsky announced that all Foneros could make money with their FON hotspots, effectively removing Linus users (Varsavsky, 2007a). Now anyone with a FON hotspot can receive $50 \%$ of the net revenues collected at their hotspot, ${ }^{14}$ payable directly to them from FON. It is noted that not all Linuses

\footnotetext{
12 blog.fon.com/en/archive/2005/11

${ }^{13}$ See www.fon.com/en/info/security for details

${ }^{14}$ elfonblog.fondoo.net/?p=106
} 
have chosen to change their status to Bill (or to actually request a share of any revenues generated through their hotspot).

FON provides a central database of hotspots on its website, ${ }^{15}$ enabling anyone who is looking for a FON hotspot to enter an address anywhere in the world and find out whether there are any FON hotspots nearby. Once a potential user locates a FON hotspot, he or she simply goes to the hotspot with a Wi-Fi device, logs in (or signs up for the service), and then has access to the internet. For aliens, there is a 15 minute free trial period, and then access is charged at $\$ 3$ or $€ 3$ per day. According to Varsavsky (2008b), FON's 'latest figures' (as of May 21,2008 ) count 830,000 Foneros, 332,000 registered hotspots, and 212,000 active hotspots. But in a blog entry in June 2008 (Varsavsky, 2008a), he states that FON has a global network of 190,000 hotspots (excluding 100,000 BT FON hotspots created through the alliance with BT). The difference in monthly figures, and between registered and active hotspots provides an indication that not all the FON routers that have been sold or given away are currently connected to the internet as live FON hotspots. As will be discussed below, not all hotspots on the map are operational.

FON is marketed in simple terms: pay for an internet connection at home, and connect from anywhere. Investors in the company include Google, Skype, BT, and several venture capital firms (Schonfeld, 2008). The concept is appealing to many, and FON has been enthusiastically embraced and promoted worldwide. Many individuals have invested significant time and effort to advance FON, for example by participating in FON's forums ${ }^{16}$ (discussing use of the network, and providing technical support to new users) and/or creating blogs promoting the use of FON. ${ }^{17}$

In the UK, internet service provider (ISP) Fondo ${ }^{18}$ promotes itself as the "UK's first FON Friendly ISP." Although many user agreements prohibit users from sharing their connections (Electronic Frontier Foundation, 2004; Gnatek, 2006; Judge, 2006), it seems that ISPs have generally turned a blind eye to FON, allowing their customers to set up FON hotspots. Varsavsky (2007b) is adamant that FON is beneficial to ISPs, and has negotiated alliances with

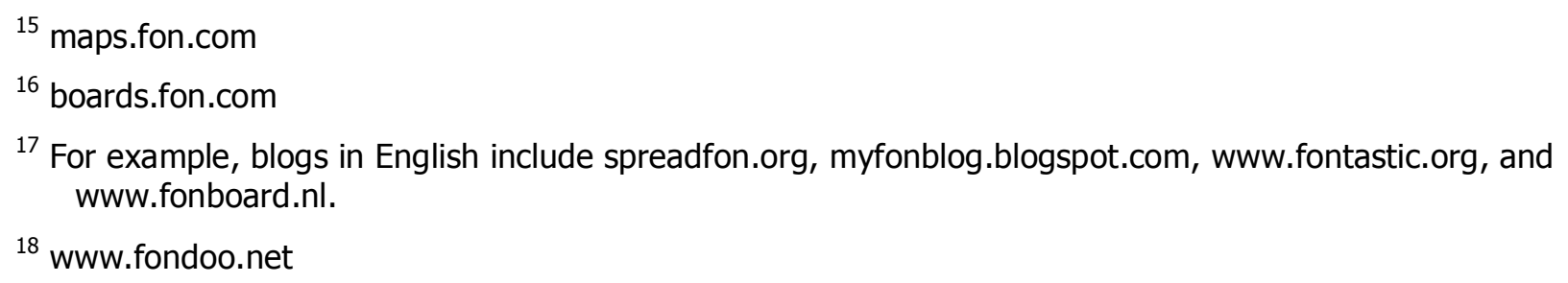


internet service providers in Russia, France, Japan, the US and the UK, as well as a deal with City of Geneva (Ante, 2007; Associated Press, 2007; Markoff, 2008). These arrangements generally make it easier for individuals to set up FON hotspots using equipment provided by their ISP, but do not open the ISPs' commercial hotspots to Foneros.

Varsavsky argues that FON can drive broadband uptake, encouraging people to get broadband at home so that they will have roaming access to broadband around the world. He reiterates that because users must have a broadband subscription they are willing to share in order to get free access to FON, FON is good for ISPs as well as individuals (Reinhardt, 2006). FON provides a way for internet providers to facilitate roaming for their clients, without negotiating formal roaming agreements with other ISPs. In addition, revenues generated by alien use of FON hotspots are shared with ISPs when the ISP has an agreement with FON.

FON generates revenues through sales of routers and antennas, as well as from access fees when aliens use FON hotspots. To date, FON has not been profitable. Indeed, FON has been losing large amounts of money since its inception, with its operating expenses far higher than its revenues:

Revenues at FON last month [April 2008] were slightly over 100K euros. Gross margins are over $70 \%$. Cash burn which was over a million euros during December was down to $480 \mathrm{~K}$ euros in April and is going down to $350 \mathrm{~K}$ euros in June. (Varsavsky, 2008b)

Although Varsavsky claims FON is reducing costs, and at this rate FON will be profitable "in the last quarter of 2009," it remains to be seen whether the company can continue to fund its expenses. "The dream of having free and ubiquitous Wi-Fi everywhere is extremely alluring and it is clear and understandable that FON has a large community of eager believers," says blogger Veldhuijzen van Zanten (2008). "FON makes for a great story," as he says, but "is that enough to build a business on?"

\section{Meraki}

Meraki's mission is to "bring affordable Internet access to the next billion people. ${ }^{19}$ Meraki provides hardware and software that enables individuals, communities and other organizations to develop their own wireless mesh networks, providing a low cost way to share broadband connections. Meraki founders Sanjit Biswas and John Bicket helped to develop Roofnet, a mesh

\footnotetext{
${ }^{19}$ meraki.com/about
} 
network that offers internet connectivity to students and staff living near MIT (Guizzo, 2003; Savage, 2006). Roofnet demonstrated that it was possible for many people to share a single internet connection, delivering relatively high quality internet access to multiple users connected over an unplanned network using multiple transmitting and receiving nodes (Bicket, Aguayo, Biswas, \& Morris, 2005).

Building on their knowledge of mesh networking developed while PhD students at MIT, Biswas and Bicket launched Meraki in 2006. Google was an early customer, using Meraki's networking kits to build their wireless network in Mountain View, CA. Google and angel investors provided start-up capital to the company. Sequoia Capital invested \$5 million in the company in early $2007,{ }^{20}$ and joined with other partners to invest $\$ 20$ million in the company in early $2008 .^{21}$

Unlike FON, Meraki is not attempting to build a universal federated broadband infrastructure. Rather, its objective is to "address the needs of the underserved market worldwide, ${ }^{\prime 22}$ by enabling communities to develop their own wireless broadband infrastructures with simple, affordable technology. Meraki "aspires to equip any interested nontechnical person to become a 'micro' service provider for his or her local community" (Stross, 2007). Its networks are operational in more than 100 countries. With three service levels (Standard, Pro and Carrier ${ }^{23}$ ), the company offers network management capacity to meet the needs of: i) individuals and local communities looking to provide internet free access; ii) individuals or groups wishing to develop more robust commercial networks with the capacity to charge for internet usage; and iii) 'carrier-class' operations looking to provide service to thousands of subscribers. In each instance, the network is built using Meraki's hardware (indoor and/or outdoor access points and repeaters, and range extending antennas), which connects automatically to Meraki's servers for network management. Meraki networks are designed to distribute wireless signals inside buildings, providing connectivity to people in their homes, rather than outside at hotspots (Stross, 2007).

\footnotetext{
${ }^{20}$ meraki.com/press-releases/2007/02/05/meraki-networks-closes-sequoia-capital-led-5-million-series-afunding

${ }^{21}$ meraki.com/press-releases/2008/01/16/meraki-to-deploy-next-generation-city-wide-free-wirelessnetwork-in-san-francisco

${ }^{22}$ web.archive.org/web/20060615054429/meraki.net

${ }^{23}$ meraki.com/oursolution/editions
} 
The key feature of a Meraki mesh network is that an internet connection is distributed within a geographic area by a collection of 'repeaters.' Branded as 'Meraki Minis,' these repeaters are installed throughout a community and automatically 'mesh' together to form a network. ${ }^{24}$ The network reconfigures itself as repeaters are added or removed from the network. At least one repeater must be connected to an internet connection (e.g. DSL or cable modem) in order to distribute the signal. As more repeaters are added to the network, the reach of the network is extended.

Noting that "most Internet users use less than $1 \%$ of their personal bandwidth limit," 25 Meraki's products allow many individuals to share a single broadband connection. CEO Biswas suggests that up to 100 people can share a single connection, by setting up a network with 10 repeaters, and allowing 10 users per repeater (Needleman, 2008). One of their early customers was NetEquality, a group providing free internet access in housing projects in Portland, OR. In the NetEquality deployment, a 100 repeater network was able to provide internet access to 400 apartments, based on just five DSL connections (Gaylord, 2007).

Meraki generates revenues by selling hardware, and it retains $20 \%$ of all revenues generated through its billing system. ${ }^{26}$ Meraki does not mandate a pricing scheme, but allows the network operator to charge whatever fees it chooses. For use on a Standard edition network (which is supported by advertising and does not allow the network operator to charge for internet access), the Meraki Mini is priced at $\$ 49$ per unit. The Pro version of the Mini currently costs $\$ 149$ per unit, and provides access to Meraki's 'hosted services. ${ }^{27}$ Meraki Pro network developers have more flexibility in managing their networks than those managing a Standard network. For instance, Pro networks can be branded, and the networks support custom advertising, different levels of Quality of Service on a single network, blocking specific users, and charging users for access to the network. All Meraki networks are connected to Meraki's servers, and are managed remotely using the web-based Meraki Dashboard.

Meraki's most visible project is the 'Free the Net' initiative in San Francisco. ${ }^{28}$ This is the only network operated directly by the company. After the city's efforts to build a citywide Wi-Fi

\footnotetext{
${ }^{24}$ meraki.com/oursolution/mesh

${ }^{25}$ meraki.com/yourgoal/openwireless

${ }^{26}$ www.practicallynetworked.com/review.asp?pid $=707$

${ }^{27}$ meraki.com/oursolution/hostedservices

${ }^{28}$ sf.meraki.com
} 
network in partnership with Google and Earthlink failed (Letzing, 2007), Meraki made the bold promise to blanket the city with Wi-Fi by the end of 2008, for a fraction of the cost of the Google-Earthlink network (Kim, 2008b). The first priority is to provide internet access to public housing projects and other underserved areas (Knight, 2008). Meraki is funding the project, estimated to cost $\$ 5$ million, as a means of testing a large scale rollout of their technologies (Needleman, 2008). It is paying for the DSL connections that provide bandwidth for the network, and is relying on the goodwill of San Franciscans to help build the mesh network by installing free Meraki Minis inside and outside their homes. Up to 15,000 Minis will need to be deployed in order for the network to cover San Francisco's 50 square mile area. The network provides users with free internet access at speeds of up to $1 \mathrm{Mbps}$, faster than those proposed through the Google-Earthlink approach, but slower than many commercial broadband services (Seybold, 2008). As of January 2008, the network was serving about 40,000 users (Meraki, 2008). In June 2008 , the number of users is closer to $100,000^{29}$.

Meraki networking technology is being used by groups like Socalfreenet.org, a non-profit group affiliated with the San Diego Computer Society. Run by volunteers, it helps bring internet access to communities by advising members on how to develop low-cost Wi-Fi networks. It works with building owners and neighbourhood residents to design mesh networks that suit local needs. Socalfreenet organizes 'installation days,' actually building the networks with local community members, and helping prospective users to get connected. The networks are designed to provide affordable, broadband coverage inside homes, and share bandwidth legally.

The 'case study' section of the Meraki Forums ${ }^{30}$ offers many additional examples of how people are using Meraki networks. Some individuals are using, or considering using Meraki's products so that they can offer fee-for-service wireless connectivity. ${ }^{31}$ Installations in apartment complexes are common, and people looking to set up new networks can seek advice in the 'tips and tricks' section. ${ }^{32}$

'Operators' are making money charging for use of their Meraki networks, although as the

\footnotetext{
${ }^{29}$ At the time of writing, Meraki provides a count of Free the Net users in the bottom left hand corner of its home page (www.meraki.com).

${ }^{30}$ forums.meraki.com/viewforum.php?f=9

${ }^{31}$ See for instance forums.meraki.com/viewtopic.php?t=2008, where an individual is considering the economics of setting up a network to provide internet access in his small town.

32 forums.meraki.com/viewforum.php?f=12
} 
example of a 'service provider' in Sydney, Australia suggests, ${ }^{33}$ the idea of 'monetizing' a network (Meraki's terminology) may be secondary to a desire to build an affordable network for use within a neighbourhood. It is also possible to generate revenues with advertising, but opinions are mixed as to whether users want advertising supported connectivity. ${ }^{34}$ As is the case with FON, it is noted that setting up a Meraki network to share an individual's internet connection may violate that individual's agreement with her or her ISP. However, most business level contracts do allow the subscriber to share the connection with others, and it appears that many network developers are seeking ways to share bandwidth legally.

\section{Assessment}

Both FON and Meraki are currently enabling thousands of people to share broadband connections. FON's main objective is to extend broadband availability for those who already have access, whereas Meraki's products are more likely to be used to provide broadband connectivity to those who were previously without access. The question of interest in this paper is whether either of these approaches is able to provide a basis for the development of good public broadband infrastructure, that is infrastructure that provides high quality service, is reliable, sustainable, and user friendly. Do these approaches offer feasible means of developing alternative broadband infrastructures, and can they help to reduce citizens' reliance upon commercial internet service providers? These questions are addressed below.

\section{Usability and Usefulness}

Evaluation begins with a discussion of usability and usefulness. If the infrastructure does not meet users' needs, other criteria such as reliability and network quality become irrelevant. A fundamental difference between FON and Meraki approaches is the location in which service is provided. Given that they are designed to be used by people the hotspot provider does not know, FON's hotspots provide service to locations outside the hotspot provider's home. While it is possible that neighbours can pick up a FON signal (especially in apartment buildings), FON's hotspots are not designed for indoor use. In addition, it is suggested that "FON does not motivate Foneros to place their hotspots in useful locations" (El Fon Blog, 2008b), that is there is little assistance provided to Foneros to improve the strength of their Wi-Fi signal, and to

\footnotetext{
33 netlife.com.au/2008/03/01/meraki-promises-meraki-delivers

${ }^{34}$ forums. meraki.com/viewtopic.php?t=2611
} 
make it more usable.

Someone looking for a FON hotspot in a particular region goes to the 'Find Wi-Fi' link on the FON site, ${ }^{35}$ locates a convenient hotspot, stands (or sits) outside the location and attempts to connect. The experience of many users suggests this can be a highly frustrating exercise, as these anecdotes illustrate:

After using the network for two months, Jan Engelke, a member from Berlin, never managed to log on to another member's connection. He is unsure of any outside activity on his own router, as FON's router firmware prohibits users who share from monitoring incoming traffic. "When you look at the FON map of Berlin, there are access points everywhere," Mr. Engelke said. "But until this date, I have never been able to access a single FON access point." (Gnatek, 2006)

I have just returned from holiday having hoped to have been able to use my new status as a member of BT FON to check my e-mails. Before I went I printed out a precise location map of the local town and during the week I spent about an hour visiting almost every one of the marked hotspots but I never succeeded in locating any of them! (Smith, 2008)

Hariri's (2007) visits to eleven addresses in Vienna identified as having FON hotspots found that only eight hotspots were active, and he could only connect to four of them. Internet access was described as 'good' at only two of the eleven hotspots tested.

This is consistent with the speculation among bloggers that FON's claims about the number of active hotspots are vastly inflated. In 2006, Mike Puchol outlined detailed calculations estimating that of the 20,000 routers shipped by FON to that date, fewer than 3,700 were actually online (Puchol, 2006). In an interview with one of the authors, El Fon blogger Chad Vanderlinden explains that "the FON maps will show all the hotspots that have been registered in an area, whether they've been up for the last hours or not. The map could include [hotspots with] months of not having been up. It could be that [the hotspot provider] got it registered, didn't like the idea, shut it off right away. Six, eight months, a year later, the icon could still be there." Veldhuijzen van Zanten (2008) concurs, noting that:

If you have set-up a FON hotspot in the past you must enter a request to have it removed from their maps. If you don't they still count you in their media and investor statistics, as a live FON Hotspot. Of the FON Hotspots that are actually live only a small percentage will be an actual hotspot when people accidentally stumble upon it.

However, the FON maps do now have the option of displaying only hotspots that have been

35 maps.fon.com/?lang=en 
active in the past hour.

These anecdotes suggest that the reality of using FON hotspots for roaming internet access does not match the promise. Usability is low, with hotspots, when they do exist, providing service to outdoor locations that may not be conducive to web surfing. Given the compromised usability of many FON hotspots, the question of usefulness also comes into play. As noted early, FON hotspots can be used for free by people who have their own hotspots. But since they have their own connections at home, other FON hotspots will only be useful when they are away from home. The question then becomes whether the hotspots are available in locations where travelers are looking for broadband connectivity. As many travelers do not stay in, or visit residential neighbourhoods, where FON hotspots are most likely to be located, it is not clear that FON hotspots are of wide use to travelers. As noted in a comment to the GigaOm blog, ${ }^{36}$

The biggest problem with FON is that they are targeting residential internet users and therefore the hotspots will be in residential areas. The stereotypical road warrior who wants to find a hotspot is going to be in the business or industrial parts of town.

The hotspots could be used by people living nearby, but in order to get free access, they would also have to have their own hotspot, in which case they wouldn't need to share with their neighbours. And for regular connectivity, FON's pricing is expensive when compared to simply acquiring a broadband connection. Observing that no one he didn't already know had ever used his FON hotspot, Vanderlinden offers this explanation: "I guess we don't have any neighbours who don't have high speed internet or Wi-Fi already."

Meraki's approach to locating access points is fundamentally different than FON's. While some people will set up hotspots that do serve outdoor areas using Meraki gear, the more common approach is to design networks to provide access to the internet from inside buildings. Most networks are built to serve specific communities, so there are fewer issues related to being able to find network access points. Meraki networks are described as "extremely easy to set up" (Berte, Puchol, \& Vanderlinden, 2007), even for people with limited technical knowledge, a conclusion also reached by Taylor (2007) and others. ${ }^{37}$ However, network builders may find that the difficulties in building a mesh network are not in the technical set up, but in the efforts needed to convince a group of individuals to become involved in the network, and to

${ }^{36}$ gigaom.com/2007/04/23/fon-time-warner-deal-confirmed

${ }^{37}$ See web reviews on Meraki products, e.g. www.the-mesh.org/tiki-index.php?page=MerakiMiniTesting, www.wi-fiplanet.com/reviews/article.php/3713946 
install repeaters inside or outside their homes. ${ }^{38}$

Local support is likely to be available to assist with any difficulties in logging in or getting connected, and users have more choice regarding the access device they use. Users need a portable device to use FON (e.g. laptop, Wi-Fi enabled smart phone), but with a Meraki network serving indoor locations, any type of computer can be used. Issues related to the availability of power, visibility of the screen, and weather do not arise when the network access point is indoors, nor is there concern about a user's device being stolen while he or she is using it an public place. Arguably, an indoor network is much more useful for everyday internet use, but it does not provide the option for access while away from home.

\section{Reliability and Quality}

Assuming that a broadband connection is configured in such a way as to be usable and useful, the next question of interest is whether the infrastructure can provide reliable, high quality service. Both FON and Meraki use existing broadband connections as the basis for their shared internet access points. So as a starting point, these networks are only as reliable as the primary connection on which they are based. With FON, this means the quality (e.g. speed) can vary from hotspot to hotspot, dependent on the quality of the provider's connection, and on how much bandwidth has been allocated to the hotspot. There are no service guarantees (Markendahl \& Mäkitalo, 2007a), and it is unlikely that people looking for very high bandwidth connections will find these through FON's hotspots. At various times, FON has given away large numbers of routers, with the objective of expanding its network. Consequently, some people may set up a FON router simply to have access to a wireless connection within their own premises, without much attention being paid to the fact that in setting up their router they have also agreed to create, and created a public hotspot. In this sort of case, there is little incentive to ensure that the connectivity provided at the hotspot is of high quality, or reliable, as long as it works to provide connectivity to the user inside his or her home.

Reliable infrastructure needs to be available on a consistent basis, but with the FON model providers have few reasons to check the reliability of their hotspot's performance. As noted earlier, there are many reports of hotspots that are either completely inactive, or visible but not usable. It is likely that most Foneros set up their routers in good faith, embracing FON's

\footnotetext{
${ }^{38}$ See forums.meraki.com/viewtopic.php?t=2320, and forums. meraki.com/viewtopic.php?t=2159.
} 
philosophy of sharing, but in reality, this does not stop an average Fonero from disconnecting, or degrading the quality of their hotspot (perhaps inadvertently). Relying on the goodwill of Foneros alone as a means of quality control does not result in the provision of good public broadband infrastructure.

Assuming that most people using Meraki networks are using them as a primary source of access in their own residences, they are less likely to face wide variation in the quality of service. Meraki's Free the Net project in San Francisco aims to deliver broadband at speeds of 1 Mbps, which is not particularly fast by today's standards. As a blog comment posted by an individual hosting a rooftop repeater says "the signal works pretty well (over $800 \mathrm{kbit} / \mathrm{sec}$ ) most days but it's still not fast enough to convince me to give up by cable connection. ${ }^{139}$

Testing of Roofnet, Meraki's predecessor, shows that network design (e.g. placement of gateways) has an impact on the quality of the network, but the overall conclusion is that the ad-hoc approach works well (Bicket et al., 2005). But Arjona et al. (2007) tested the quality of a Meraki network in 2006, and concluded that "single-radio mesh architecture [as used in the Meraki Mini] is not suitable for building large outdoor networks" (p. 545). According to Gabriel (2008), there are "huge issues of coverage, quality, signal strength and interference, ...worsened by the somewhat random network planning enforced by organic mesh approaches." She does note that Meraki's technology and extensive planning for the San Francisco deployment will help improve the quality of the network, but argues that an ad-hoc network reliant upon users to host network components "will never be able to deliver the quality, security and reliability that most people take for granted from their access services."

The fragility of the network is illustrated with an anecdote from the NetEquality project, where the director:

remembers "freaking out" ... when several of his networks suddenly collapsed. "Nodes were going down all over," he says. "It turned out that since we just plugged the boxes into normal outlets in each apartment, the residents decided they'd rather plug in their Christmas lights. But so many unplugged them that they were knocking out access to most of their neighbors as well." (Gaylord, 2007)

While the Meraki approach can deliver affordable broadband, it appears that affordability comes with lower quality and reliability. It is not clear whether it is possible, or likely, that the quality of meshed network services will increase in future.

${ }^{39}$ Comment by rumblpak at gigaom.com/2008/06/11/meraki-unwires-sfs-neediest. 


\section{Sustainability}

Are FON and Meraki infrastructures built to last? In the case of FON, the answer is likely no. As noted above, despite FON founder Varsavsky's optimism that FON will be profitable by the last quarter of 2009, there are no guarantees that the company will exist in the long term. As Vanderlinden argues (EI Fon Blog, 2008a), the only way that FON provides value to the FON community is by maintaining the database of FON hotspots, and by providing the authentication and billing system. It appears that the database is not particularly accurate, and few people draw much benefit from the existence of the network (devaluing the billing and authentication infrastructure). FON is highly reliant upon the goodwill of its community members to keep the infrastructure in place, and this goodwill is dissipating. ${ }^{40}$ There is little loyalty to FON, and limited economic incentives for Foneros to remain committed to the project (Markendahl \& Mäkitalo, 2007a).

As is evident in the FON discussion boards ${ }^{41}$ and on blogs like El Fon ${ }^{42}$, many individuals have invested enormous personal effort into building a community around FON.

The FON Movement is the active members of the discussion boards and other Wi-Fi communities who maintain the enthusiasm and volunteer their efforts for a common cause. ${ }^{43}$

These individuals are frustrated that FON does not listen to their suggestions for improving the FON user experience, and feel that the company is no longer about community, but is simply another business venture for its founder. As one commenter says in response to a blog posting lamenting the commercialization of FON and the demise of 'the Wi-Fi Revolution, "The thing is that many people around the world were inspired by the very idea of FON revolution. And now there is no revolution. ${ }^{\prime \prime 4}$ Many technically savvy people joined FON to out of curiosity, and/or to get a free or cheap router, and have since 'hacked' the FON router to better suit their own needs and interests. ${ }^{45}$ In some cases, these hacked routers are used to provide free $\mathrm{Wi}-\mathrm{Fi}$,

\footnotetext{
${ }^{40}$ See the Community Resistance section of the El Fon Blog, for example: elfonblog.fondoo.net/?cat=44.

${ }^{41}$ boards.fon.com/viewforum.php?f=1

42 elfonblog.fondoo.net

43 elfonblog.fondoo.net/?p=48

${ }^{44}$ See www.milanin.com/members/andrey.golub/weblog/529.html.

${ }^{45}$ See for example fonerahacks.com/index.php/Tutorials-and-Guides/Full-DD-WRT-Flash-Guide.html, dltv.wordpress.com/off-the-wall/a-guide-to-hacking-the-la-fonera-wireless-router and global.freifunk.net/item/the_fonera_hacked_to_run_openwrt.
} 
outside the FON branded community, ${ }^{46}$ but others become private routers, providing no public Wi-Fi access. The long-term prospects for the FON network seem uncertain at best, suggesting this is not an approach to build sustainable infrastructure.

The Meraki approach to network development is much more grounded in local communities, and the company is generally well-regarded by other community wireless networking groups. ${ }^{47}$ Although there are likely to be intermittent issues with individuals disconnecting their Meraki Minis, the mesh network approach makes it easier for the person maintaining the network to ensure continued coverage. It is suggested that a Meraki network can be as sustainable as the community (or individual) developing it, but there is one concern about the long term viability of the Meraki model. A Meraki network is developed by a community or individual, but the management of the network is done through Meraki's servers. A Meraki network will not work independently of Meraki. For those charging for network access, the current 'commission' fee paid to Meraki is $20 \%$ of revenues, but it is possible that this could change (either increasing or decreasing). In addition, pricing for network components (e.g. Meraki Minis) is determined by the company, and in the past has been subject to steep increases. ${ }^{48}$

For low-income communities, an increase in the cost of providing connectivity may not be trivial. When Meraki changed its pricing model, in late 2007, there was a great deal of anger among the people who were using Meraki gear to build community networks. ${ }^{49}$ Relying upon a single company to support infrastructure creates a risk for long-term sustainability. Changes in corporate policy may change the economics of providing service using a particular infrastructure, or the demise of the company might mean that the infrastructure becomes unusable. In a thoughtful post to the Meraki forum ${ }^{50}$, Dieter Birk notes that "people who have money have choices and will migrate to stable models by competitors," and observes that Meraki's business model is not unique. The company is young, and some believe its

\footnotetext{
${ }^{46}$ www.cuwin.net/node/324

${ }^{47}$ Comment by Dana Spiegel, from NYCWireless, in an interview with one of the authors.

48 The price per Mini increased from $\$ 49$ to $\$ 149$ for the professional license. For anyone building a network that would charge for network access, this tripled the cost per repeater.

${ }^{49}$ See article and comments on the GigaOM blog: gigaom.com/2007/10/07/meraki-price-hike, as well as forums.meraki.com/viewtopic.php?t=1841, and freethenet.scribblewiki.com/Meraki_Pro_Mini_Position.

${ }^{50}$ forums.meraki.com/viewtopic.php?t=2159
} 
management team is inexperienced. ${ }^{51}$ Although it is funded by big names in the technology sector, the company may not exist in its current form, or providing the same sort of service, in a few years.

\section{Ubiquity}

In order to build an infrastructure that could offer an alternative to the existing commercial offerings, ubiquitous (or locally ubiquitous) coverage is necessary. In promoting FON as a means of providing broadband connectivity to individuals as they travel around the world, there is an expectation that coverage is available where those individuals travel. Skype's investment in FON, ${ }^{52}$ and FON's promotion of a Skype Wi-Fi phones ${ }^{53,54}$ could lead users to the conclusion that there is sufficient network coverage available to allow individuals to use the Skype/FON service as an alternative to the mobile phone network. When FON signed an agreement with ISP BT in the UK in 2007, the possibilities for use of Skype over the larger BT-FON network was seen as a important benefit. ${ }^{55}$ But despite FON's alliance with BT, and other ISPs around the world, the FON network coverage is far from ubiquitous. Indeed, most people looking to use the FON 'network' have extreme difficulties in locating a single FON hotspot that is usable (let alone in a convenient place). FON's offering to date is certainly not a feasible alternative to existing infrastructure provided by internet service providers and mobile operators, and the business model is not likely to enable the worldwide connectivity Varsavsky envisioned for his 'Wi-Fi revolution.'

Although Meraki wants to 'connect the next billion' people to the internet, their approach is not attempting to build global ubiquitous infrastructure. Instead, most Meraki networks are being developed to provide coverage within communities, focusing on providing connectivity to fixed locations rather than to support roaming. Network operators may choose to open their networks to individuals looking for network access in a specific location, but there is no effort among operators to provide ubiquitous coverage on any sort of global level, with any kind of global authentication process. The Free the Net project is trying to provide ubiquitous coverage

\footnotetext{
${ }^{51}$ forums.meraki.com/viewtopic.php?t=2159

52 www.socialpatterns.com/technology/fon-google-skype-and-why-it-matters

${ }^{53}$ Rlchtel, 2006.

${ }^{54}$ shop.fon.com/FonShop/shop/GB/ShopController?view=product\&product=PRD-PHN01

${ }^{55}$ share.skype.com/sites/uk/2007/10/bt_fon_more_skype.html
} 
within San Francisco (but has not yet achieved this objective), and other groups, like Free Sydney Wireless ${ }^{56}$, and Free Wireless Canberra ${ }^{57}$ (both in Australia), are attempting to provide blanket coverage across municipal areas (Sharwood, 2008). For some users, citywide coverage may be sufficiently ubiquitous to provide value (e.g. a person could potentially replace a standard mobile phone with a Wi-Fi one), but the network must also be sufficiently robust to support desired activities in all locations.

\section{Security}

Individuals connecting to the internet using either FON or Meraki infrastructures are sharing a connection with someone else. In the case of FON, how can hotspot users be certain that the hotspots they are connecting to are really part of the FON community, and not set up by an untrusted source? In addition, how does the person providing the connection know that the connection really is secure, i.e. that the hotspot user does not have unauthorized access to the Fonero's data? Finally, for someone using a FON hotspot, is the data transfer secure? These are all important questions (see Krag, 2006, for an overview of security issues in open wireless networks) that impact the viability of FON as a provider of good public broadband infrastructure. Members of the FON community have asked questions about its security since its inception, and according to FON websites, "FON is safe. ${ }^{\prime 28,59}$ Martin Varsavsky writes in his blog that worrying about security "is really unnecessary, ${ }^{\prime \prime 60}$ an approach that some security experts agree with (e.g. Schneier, 2008). But Varsavsky's platitudes do not satisfy many in the FON community. FON networks are not encrypted, and there is evidence (e.g. the hacked routers mentioned above, Björck's 2007 assessment of FON security) to suggest that not all aspects of the network are secure. Members of the FON community have suggested to FON that support for virtual private networks (VPNs) could be added to the Fonera to improve security for hotspot users, but this suggestion has not been acted upon. The fact that people continue to participate in the FON community suggests that there is a comfort level with FON's approach to security, but there is room for improved security measures.

\footnotetext{
${ }^{56}$ blog.freesydneywireless.com/about/

57 freecanberrawireless.net/about/

58 english.martinvarsavsky.net/fon/is-fon-safe.html

${ }^{59}$ www.fon.com/en/info/security

${ }^{60}$ english.martinvarsavsky.net/fon/fon-security.html
} 
When Meraki gear is used by a community to set up a wireless network, the identity of the network operator is not in question. Meraki does allow encryption of the private side of its networks, requiring the operator to provide an access key to users. ${ }^{61}$ There does not appear to have been much discussion of the security of Meraki networks. An Australian blogger ${ }^{62}$ asks the question 'Are Merakis secure?' and concludes that:

in the context of the myriad of other information security risks with your computer and your network ... this [accessing the internet using a Meraki network] is really nothing to be worried about.

Wireless Ypsi, a Meraki network providing Wi-Fi connectivity in Ypsilanti, Michigan, notes that their network "provides the same level of wireless security as other open wireless access points," and recommends that users "practice safe Internet usage when using any wireless network. ${ }^{163}$ It is difficult to assess the security of FON and Meraki networks, thus the advice to use caution in connecting to these (and other) wireless networks is appropriate.

\section{Affordability}

FON's focus is on providing Wi-Fi everywhere, but there is no evidence that there is a focus on ensuring that 'Wi-Fi everywhere' is affordable to users. As has been explained, in order to get 'free' roaming broadband through FON, a Fonero must already have a broadband connection with an active La Fonera router attached to it, operating a FON hotspot. So FON members are paying their own internet service provider for internet access, in addition to any costs that were incurred in obtaining a FON router. That said, they should be able to avoid additional costs for roaming internet access, if they can find and use FON hotspots while away from home.

For aliens who choose to connect to FON hotspots (if they can find them), there is a 15 minute free trial period allowed each day, and in addition, FON now provides free access to Gmail, Google maps, news and search. ${ }^{64}$ Arguably, given these free offerings, FON does provide affordable connectivity to users to carry out basic online activities. But using FON as a regular paid user does not make much sense, as there are cheaper, more reliable options available.

\footnotetext{
${ }^{61}$ Search for 'security' in the Meraki forum: meraki.com/help/kb.

62 freecanberrawireless.net/2008/01/are-merakis-secure/

${ }^{63}$ wireless.ypsi.com/network.html\#security

${ }^{64}$ blog.fon.com/en/archive/general/gmail-and-fon.html
} 
FON's daily charge is $€ 3$ or $\$ 3$ USD. For anyone needing to connect for more than a few days, it is likely they would be better served with a mobile broadband connection (e.g. 3G/HSDPA USB modem or data card) from a cellular telephony provider, or by a contract with a commercial hotspot operator (e.g. Boingo in the US, The Cloud in the UK ${ }^{65}$ ).

The pricing of access to Meraki networks is set at the discretion of the network operator. Some Meraki networks offer free internet access (e.g. Free the Net in San Francisco), others charge users a nominal fee for access. Compared to other mesh networking technologies (e.g. Tropos or Motorola), Meraki networks are inexpensive to set up. Meraki's philosophy is to enable the creation of low cost internet access networks, and it seems that many of its customers develop networks in this spirit, providing affordable connectivity for their users.

\section{Discussion}

FON and Meraki have different missions, and different approaches to building infrastructure. Because both companies rely upon existing broadband infrastructure to provide the basic connectivity to their shared networks, neither can be said to be providing a truly alternative approach to existing internet service providers. However, both companies have the potential to extend the reach of existing broadband infrastructures, providing users with service that may be more affordable than alternative options (Meraki), or by providing coverage over a wider geographic area (FON). The table below summarizes the differences in the two approaches, when compared on aspects that are fundamental to the development of good broadband infrastructures.

\begin{tabular}{|l|l|l|l|}
\hline \hline & FON & Meraki & Comments \\
\hline \hline Purpose/Mission & $\begin{array}{l}\text { Extend community } \\
\text { members' broadband } \\
\text { connectivity, provide } \\
\text { roaming access for } \\
\text { members, provide } \\
\text { connectivity to non- } \\
\text { members }\end{array}$ & $\begin{array}{l}\text { Provide equipment to enable } \\
\text { communities to develop } \\
\text { their own broadband } \\
\text { infrastructures }\end{array}$ & $\begin{array}{l}\text { Both approaches build } \\
\text { their infrastructure on } \\
\text { top of that provided by } \\
\text { another Internet Service } \\
\text { Provider, neither group } \\
\text { is developing their own } \\
\text { 'backhaul' to support } \\
\text { their shared internet } \\
\text { connections. }\end{array}$ \\
\hline
\end{tabular}

${ }^{65}$ www.boingo.com, www.thecloud.net/About-us. 


\begin{tabular}{|c|c|c|c|}
\hline & FON & Meraki & Comments \\
\hline $\begin{array}{l}\text { Usability and } \\
\text { Usefulness }\end{array}$ & $\begin{array}{l}\text { Usability is compromised } \\
\text { by the outdoor location of } \\
\text { most hotspots, poor } \\
\text { information on hotspot } \\
\text { availability, and technical } \\
\text { problems in connecting to } \\
\text { hotspots. Most hotspot } \\
\text { users already have } \\
\text { connectivity at home, and } \\
\text { the location of FON } \\
\text { hotspots may not be } \\
\text { useful to potential users. }\end{array}$ & $\begin{array}{l}\text { Meraki networks likely offer } \\
\text { better usability than FON } \\
\text { networks. Meraki hardware } \\
\text { is designed to provide } \\
\text { connectivity to users inside } \\
\text { their houses, increasing } \\
\text { flexibility regarding choice of } \\
\text { access device, and } \\
\text { improving usefulness by } \\
\text { providing connectivity to the } \\
\text { home. }\end{array}$ & $\begin{array}{l}\text { Despite FON's promise } \\
\text { of providing roaming } \\
\text { internet access, for } \\
\text { many users it has } \\
\text { proved to be useless at } \\
\text { providing extended } \\
\text { network access. Meraki's } \\
\text { approach appears to } \\
\text { offer a better solution } \\
\text { for improved access. }\end{array}$ \\
\hline $\begin{array}{l}\text { Reliability and } \\
\text { Quality }\end{array}$ & $\begin{array}{l}\text { FON has no means of } \\
\text { ensuring quality of service } \\
\text { (QoS) at its hotspots. } \\
\text { Building a network based } \\
\text { on users' goodwill does } \\
\text { not produce reliable } \\
\text { infrastructure. }\end{array}$ & $\begin{array}{l}\text { There are concerns that } \\
\text { Meraki's approach cannot } \\
\text { provide very high speed } \\
\text { coverage, and that the mesh } \\
\text { architecture cannot } \\
\text { guarantee QoS, suggesting } \\
\text { that a wireless network is } \\
\text { not as good as a wired one. } \\
\text { Reliability is impacted by } \\
\text { users disconnecting network } \\
\text { equipment. }\end{array}$ & $\begin{array}{l}\text { Meraki networks can be } \\
\text { more easily managed, } \\
\text { but the quality of a } \\
\text { shared wireless } \\
\text { connection cannot match } \\
\text { that of a direct, wired } \\
\text { connection. }\end{array}$ \\
\hline Sustainability & $\begin{array}{l}\text { The FON network appears } \\
\text { to be on tenuous ground. } \\
\text { Despite efforts to increase } \\
\text { the number of hotspots, } \\
\text { its low usability means } \\
\text { there are few incentives } \\
\text { for existing hotspot } \\
\text { providers to remain in the } \\
\text { community. Its primary } \\
\text { supporters feel alienated. } \\
\text { There is also concern } \\
\text { about the company's } \\
\text { finances. }\end{array}$ & $\begin{array}{l}\text { Meraki's approach is } \\
\text { grounded in community } \\
\text { development. The weakness } \\
\text { in its model is that network } \\
\text { developers are dependent } \\
\text { upon Meraki's central control } \\
\text { of all networks developed } \\
\text { using Meraki technology. } \\
\text { This makes the networks } \\
\text { vulnerable to change at } \\
\text { Meraki, and could make } \\
\text { further network } \\
\text { development unaffordable if } \\
\text { Meraki raised it prices again. } \\
\text { As a new company, there } \\
\text { are concerns about } \\
\text { inexperienced management, } \\
\text { and uncertainty about } \\
\text { whether the company will } \\
\text { exist in a few year's time. }\end{array}$ & $\begin{array}{l}\text { Neither approach is likely } \\
\text { to enable the } \\
\text { development of highly } \\
\text { sustainable } \\
\text { infrastructures. Meraki } \\
\text { appears more stable } \\
\text { than FON at present. }\end{array}$ \\
\hline
\end{tabular}




\begin{tabular}{|c|c|c|c|}
\hline & FON & Meraki & Comments \\
\hline Ubiquity & $\begin{array}{l}\text { FON's ability to create a } \\
\text { 'Wi-Fi revolution' relies } \\
\text { upon ubiquity of its } \\
\text { hotspots. But FON suffers } \\
\text { from a lack of critical } \\
\text { mass. It has insufficient } \\
\text { scale to provide good } \\
\text { infrastructure. }\end{array}$ & $\begin{array}{l}\text { Meraki's technologies are } \\
\text { being used in some } \\
\text { attempts to provide 'local' } \\
\text { ubiquity. Meraki is not } \\
\text { attempting to build networks } \\
\text { that provide coverage across } \\
\text { large geographic regions, } \\
\text { and is not attempting to } \\
\text { provide roaming access for } \\
\text { users. }\end{array}$ & $\begin{array}{l}\text { Meraki and FON have } \\
\text { different objectives. FON } \\
\text { needs to offer ubiquitous } \\
\text { service to provide real } \\
\text { value to users, but does } \\
\text { not deliver. Meraki's } \\
\text { approach is more local in } \\
\text { nature and seems to be } \\
\text { more achievable. }\end{array}$ \\
\hline Security & $\begin{array}{l}\text { Flaws have been } \\
\text { identified. }\end{array}$ & No specific flaws identified. & $\begin{array}{l}\text { It is difficult to } \\
\text { determine the extent to } \\
\text { which network security } \\
\text { is a concern. As some } \\
\text { commentators note, no } \\
\text { wireless infrastructure is } \\
\text { considered to be highly } \\
\text { secure, thus neither } \\
\text { approach rates well on } \\
\text { this element of public } \\
\text { infrastructure provision. }\end{array}$ \\
\hline Affordability & $\begin{array}{l}\text { Not a key priority for } \\
\text { FON, but the model } \\
\text { should enable Foneros to } \\
\text { get free internet roaming. } \\
\text { Use of FON hotspots for a } \\
\text { daily fee is expenses. }\end{array}$ & $\begin{array}{l}\text { Meraki technologies are } \\
\text { designed to help } \\
\text { communities build low-cost } \\
\text { infrastructure. Pricing for } \\
\text { network access is set by the } \\
\text { network operator. }\end{array}$ & $\begin{array}{l}\text { The approaches are } \\
\text { different. FON should be } \\
\text { able to provide free } \\
\text { roaming access to } \\
\text { Foneros (but is } \\
\text { hampered by usability } \\
\text { problems). Meraki } \\
\text { enables the development } \\
\text { of cheap infrastructures. }\end{array}$ \\
\hline
\end{tabular}

The assessment offered here suggests that the FON approach is seriously flawed. The most pressing concern is with usability of its hotspots. Given that many users have found the infrastructure to be close to, or actually, unusable, the other flaws in the approach are incidental at present. In order for FON to survive, its infrastructure must be accessible to its community members, when and where they want to use it. But this problem is not one that FON can easily remedy. Even if it were to be remedied, FON would also require a massive increase in the availability of its hotspots to provide anything close to ubiquitous coverage. Approaches to do this through alliances with ISPs have not delivered, and it seems that momentum is leaving 'the Wi-Fi revolution.' Competition from mobile broadband services is reducing the need for wireless hotspots, and even if FON was to increase its network footprint it is not clear that this would result in greatly increased revenues. As discussed by Middleton 
(2007), there are many problems with the existing approach to providing wireless internet infrastructure through outdoor hotspots. FON's approach does not mitigate these problems. Some bloggers believe that founder Varsavsky is preparing the company for sale, ${ }^{66}$ but this analysis suggests that there is currently little of value that would interest potential buyers. However, one positive aspect of FON is that it has encouraged a wide community of users to become more involved in developing broadband infrastructures. As demonstrated in discussions on the FON boards, there is a great deal of expertise evident among highly engaged Foneros, and this expertise can be channeled into other projects to improve the availability of broadband infrastructure.

In comparison to FON, Meraki's approach seems to be better suited to enable the development of broadband infrastructure in locations where it is needed, offering good functionality to potential users. Meraki networks do not rely upon the promise of reciprocity to extend their reach, but network developers do need to convince community members to host Meraki equipment in order to build out the mesh. The community-centric approach means that users may be more committed to supporting the network and working with its developers to ensure its sustainability, but developers are vulnerable to changes by the corporation that would affect the economics of extending and operating their networks. However, the affordable internet access provided over networks built with Meraki technology comes at the price of reliability and quality of service. Wireless mesh networks do not offer the reliability of wired connections, and it is difficult to ensure quality of service with this approach. As compared to no broadband access, a wireless mesh connection offers a good solution for users. While the technology has some flaws, it is suggested that users do benefit from a community-centric approach to developing local infrastructures for local needs. In addition, it is possible that with the expertise and community support generated through the development of mesh networks, communities can go on to build more robust technical infrastructures on a low-cost basis. Wireless mesh networks do help to extend broadband connectivity, but are unlikely to be the technology of choice for provisioning broadband in the longer term. The Meraki philosophy of enabling communities to build low-cost infrastructures could be carried over to new networking technologies (by Meraki or other groups), perhaps by finding ways to reduce the costs of delivering fibre connectivity within communities.

\footnotetext{
${ }^{66}$ This was discussed in our interview with Chad Vanderlinden.
} 


\section{Conclusion}

The question posed in the title of this paper is "Is it good to share?" FON offers individuals a vision of access to broadband technology anywhere around the world. To join this community, all that is necessary is for an individual to share his or her own connectivity with anyone else who might be interested. In return, this individual can get access to connectivity from others. This reciprocal arrangement sounds appealing, but as the analysis presented in this paper shows, the reality does not live up to the promise. Few individuals either share their own connections through FON, or successfully connect to other connections. So is it good to share? In the FON context, there is a remote possibility that sharing may provide some benefit to users, and there is no hard evidence that sharing detracts from individuals' personal use of their broadband connections. But as a means of extending access to useful, reliable and sustainable broadband infrastructure, the FON approach has been a failure. This does not mean that sharing broadband connections is necessarily a bad idea, but the experience of FON, a wellfunded company led by an experienced entrepreneur, suggests that to develop any sort of large scale network based on aggregating individual connections is very very difficult. The practical challenges of harnessing the bandwidth of individual connections, to extend access to this infrastructure, are serious, and it does not seem likely that a community-led approach can overcome the many obstacles that are in place.

Meraki's approach is different in that individual users are not necessarily being asked to share their private connections. Instead, extended connectivity is provided within communities by sharing a small number of broadband connections. The cost of acquiring this network connectivity is shared within the community. While individuals can of course use Meraki gear to allow others to access their broadband connection (for free, or for a fee), the basic approach for building a Meraki network does not require the sort of reciprocity expected in the FON community. What it does require however is that people living within range of the network install Meraki Minis inside or outside their premises, in order to extend the reach of the mesh network. This sort of cooperation at a community level is required to build a Meraki network. People served by a Meraki network may be asked to participate by hosting networking equipment, but they are not required to provide bandwidth to the network. The bandwidth for the shared connection is sourced by the network operator, and users of the network get the benefits of shared access. So for people who can access a Meraki network, there are benefits to sharing. But as has been discussed, a network developed using this sort of technology is not as 
robust as wired alternatives. Meraki networks do create environments where it is good to share, but the overall quality of the network could be improved.

The two case studies presented here show the difficulties for citizens in developing their own broadband infrastructures. Although the two approaches have different purposes, each is an effort to extend broadband connectivity through community action. Each approach offers a measure of success (Meraki more so than FON), but neither can be considered as a completely effective way to develop good public broadband infrastructure. These findings are consistent with Sandvig's observations on infrastructure development. He asks:

When is a decentralized, cooperatively run communication infrastructure a significant alternative to the centrally driven, commercial systems that have historically prevailed? The research literature on utility and communication infrastructures answers, "almost never," or "only in the early stages of a system." (Sandvig, 2004, p. 580)

Varsavsky proudly describes FON as being "like a telephone company built by the people" (Markoff, 2008). The problem is that FON is exactly like a telephone company built by individuals, without the benefit of the expertise, resources, and scale that a commercial operator can build. This observation does not suggest that infrastructures must be built by the commercial sector, rather that there is a need for scale, and for central coordination that are not easily achieved by the ad-hoc nature of many community efforts. Both FON and Meraki are extending broadband connectivity through shared networks, but neither is able to develop infrastructure that meets all criteria of good public broadband infrastructure.

\section{Bibliography}

Ante, S. E. (2007). FON Is Building a Global Network of Wi-Fi Hotspots - in the Homes of Its Members. Business Week, 4054, 42.

Arjona, A., Westphal, C., \& Takala, S. (2007). Empirical Analysis of the Single-Radio Mesh Architecture: Performance Limitations and Challenges, Proceedings of the 2007 international conference on Wireless communications and mobile computing. Honolulu, Hawaii, USA: ACM.

Associated Press. (2007, 24 April). Time Warner Broadband Deal to Allow Users to Share Access. New York Times.

Atkinson, R. D. (2007). Framing a National Broadband Policy. CommLaw Conspectus, 16(1), 145-177.

Berte, D., Puchol, M., \& Vanderlinden, C. (2007). Wireless Is Fun Podcast No. 2. Retrieved 10 June, 2008, from http://wirelessisfun.com/wp-content/uploads/2007/04/WiF_pod2Chad-vs-Mike.mp3. 
Bicket, J., Aguayo, D., Biswas, S., \& Morris, R. (2005). Architecture and Evaluation of an Unplanned 802.11b Mesh Network. Paper presented at the 11th Annual International Conference on Mobile Computing and Networking, Cologne, Germany.

Bina, M., \& Giaglis, G. M. (2005). Emerging Issues in Researching Community-Based WLANs. The Journal of Computer Information Systems, 46(1), 9-16.

Bina, M., \& Giaglis, G. M. (2006). Unwired Collective Action: Motivations of Wireless Community Participants. Paper presented at the International Conference on Mobile Business, Copenhagen.

Björck, F. (2007). FON Security Scenarios. Retrieved 10 June, 2008

Bleha, T. (2005). Down to the Wire. Foreign Affairs, 84(3), 111-124.

Breitbart, J., Lakshmipathy, N., \& Meinrath, S. (2007). The Philadelphia Story: Learning from a Municipal Wireless Pioneer. Washington, DC: New America Foundation.

Cox, J. (2008, 21 April). Municipal Wi-Fi 2.0; as Large-Scale, for-Profit Projects Falter, Innovative New Models Emerge. Network World, 22.

Crow, B., \& Miller, T. (2008). Île Sans Fil Case Study Map. Toronto: Community Wireless Infrastructure Research Project.

Damsgaard, J., Parikh, M. A., \& Rao, B. (2006). Wireless Commons Perils in the Common Good. Association for Computing Machinery. Communications of the ACM, 49(2), 105-109.

Danigelis, A. (2008). 10 Cities with Widespread Wireless Internet. Retrieved 10 June, 2008, from http://dsc.discovery.com/technology/tech-10/wireless-cities-top.html.

Efstathiou, E. C., Elianos, F. A., Frangoudis, P. A., Kemerlis, V. P., Paraskevaidis, D. C., Polyzos, G. C., et al. (2006a). Building Secure Media Applications over Wireless Community Networks.

Efstathiou, E. C., Elianos, F. A., Frangoudis, P. A., Kemerlis, V. P., Paraskevaidis, D. C., Stefanis, E. C., et al. (2006b). Public Infrastructures for Internet Access in Metropolitan Areas, Proceedings of the 1st international conference on Access networks. Athens, Greece: ACM.

El Fon Blog. (2008a). Fon Does Not Split Money 50/50. Retrieved 31 May, 2008, from http://elfonblog.fondoo.net/?p=106.

El Fon Blog. (2008b). NYT Article Flubs FON Statistics. Retrieved 31 May, 2008, from http://elfonblog. fondoo.net/?p=109.

Electronic Frontier Foundation. (2004). Wireless-Friendly ISPs. Retrieved 10 June, 2008, from http://w2.eff.org/Infrastructure/Wireless cellular radio/wireless friendly isp list.html.

Fleishman, G. (2006). St. Cloud Says 77\% of Households Registered for Free Wi-Fi. Retrieved 15 March, 2008, from http://wifinetnews.com/archives/006951.html.

Forlano, L. (2008). Anytime? Anywhere?: Reframing Debates around Municipal Wireless Networking. Journal of Community Informatics, 4(1).

Forsberg, D. (2007). Secure Distributed AAA with Domain and User Reputation. Paper presented at the IEEE International Symposium on a World of Wireless, Mobile and Multimedia Networks. 
Francis, J. C., Elnegaard, N., Eskedal, T. G., \& Venturin, R. (2006). Business Opportunities of Open Broadband Wireless Access Networks, Proceedings of the 2006 workshop on broadband wireless access for ubiquitous networking. Alghero, Italy: ACM.

Gabriel, C. (2008). With the Metrozone Bubble Burst, Does Meraki Offer a New Way Forward? Retrieved 10 June, 2008, from http://www.arcchart.com/blueprint/show.asp?id=444.

Gaylord, C. (2007, 12 December). A Low-Cost Route to the Web. Christian Science Monitor, p. 13.

Gnatek, T. (2006, 27 September). A Worldwide Network Built on People Power. New York Times.

Goldman, G. (2008). Digital Inclusion: Message for Partners and Subscribers. Retrieved 10 June, 2008, from http://www.wirelessphiladelphia.org/blog_detail.cfm/blog/70.

Guizzo, E. (2003, 29 August). Networking from the Rooftop. Technology Review.

Hariri, K. (2007). Road Test: Availability of FON Hotspots in Vienna. Retrieved 10 June, 2008, from http://www.hariri.at/kyros/fon/Road_test_availability_FON_hotspots_in_Vienna.pdf.

Hudson, H. E. (2006). Lessons from the Left Coast: San Francisco's Community Wireless Broadband Initiative, Telecommunications Policy Research Conference (TPRC). Washington, DC

Hultell, J., Zander, J., \& Markendahl, J. (2007). Competition and Cooperation in Wireless MultiAccess Networks. In Fitzek, F. H. P. \& Katz, M. D. (Eds.), Cognitive Wireless Networks: Concepts, Methodologies and Visions Inspiring the Age of Enlightenment of Wireless Communications (pp. 109-132): Springer.

Hüsig, S., Hipp, C., \& Dowling, M. (2005). Analysing Disruptive Potential: The Case of Wireless Local Area Network and Mobile Communications Network Companies. $R \& D$ Management, 35(1), 17-35.

International Telecommunication Union. (2004). The Portable Internet. Geneva: ITU.

Judge, P. (2006). Guerrilla Telco Pushes Broadband 'Sub-Letting'. Retrieved 31 May, 2008, from http://news.zdnet.co.uk/0,1000000073,39283521,00.htm.

Kim, R. (2008a, 11 June). Cities Have to Bid Bye-Bye to Free Wi-Fi. San Francisco Chronicle.

Kim, R. (2008b, 4 January). S.F. Is Offered Citizen-Based Wi-Fi for Free. San Francisco Chronicle, p. A1.

Knight, H. (2008, 12 June). Different Sort of Free Wi-Fi Starts to Thrive. San Francisco Chronicle.

Krag, T. (2006). The Security Challenge of Open Wireless Networks. Retrieved 10 June, 2008, from http://www.multiplicity.dk/2006/03/the-security-challenge-of-open-wirelessnetworks/.

Letzing, J. (2007). Google-Earthlink San Francisco Wi-Fi on Hold. Retrieved 29 August, 2007, from http://www.marketwatch.com/news/story/google-earthlink-san-francisco-wi-fiproject/story.aspx?guid=\%7B305EBE69-80DA-44B7-8068-696F7F7540A3\%7D.

Manshaei, M. H., Freudiger, J., Felegyhazi, M., Marbach, P. A., \& Hubaux, J.-P. A. (2008). 
Wireless Social Community Networks: A Game-Theoretic Analysis. Paper presented at the IEEE International Zurich Seminar on Communications

Markendahl, J., \& Mäkitalo, Ö. (2007a). Analysis of Business Models and Market Players for Local Wireless Internet Access. Paper presented at the 6th Conference on Telecommunication Techno-Economics.

Markendahl, J., \& Mäkitalo, Ö. (2007b). Business Model Analysis for Local Access Provisioning. Paper presented at the IEEE 18th International Symposium on Personal, Indoor and Mobile Radio Communications.

Markendahl, J., \& Mäkitalo, Ö. (2007c). Customer Relations and Business Role Interaction for Wireless Access Provisioning in Local Environments. Paper presented at the LA Global Mobility Roundtable, Los Angeles.

Markoff, J. (2008, 25 May). Global Dreams for a Wireless Web. New York Times.

Meraki. (2008). Meraki to Deploy Next-Generation City-Wide, Free Wireless Network in San Francisco. Retrieved 10 June, 2008, from http://meraki.com/pressreleases/2008/01/16/meraki-to-deploy-next-generation-city-wide-free-wireless-networkin-san-francisco/.

Middleton, C., Longford, G., Clement, A., Potter, A. B., \& Crow, B. (2006). ICT Infrastructure as Public Infrastructure: Exploring the Benefits of Public Wireless Networks. Paper presented at the Telecommunications Policy Research Conference, Arlington, VA.

Middleton, C. A. (2007). A Framework for Investigating the Value of Public Wireless Networks, 35th Research Conference on Communication, Information and Internet Policy. Arlington, VA: TPRC.

Needleman, R. (2008). Meraki Is Offering Free Wi-Fi to San Francisco. Why? Retrieved 9 June, 2008, from http://www.webware.com/8301-1_109-9945540-

2.html?part=rss\&tag = feed\&subj=Webware.

Ohira, K., Huang, Y., Komura, T., \& Okabe, Y. A. (2007). Loosely Trusted yet Secure Roaming Architecture for Public Wireless Internet Service. Paper presented at the Second International Conference on Informatics Research for Development of Knowledge Society Infrastructure.

Potter, A. B., \& Clement, A. (2007). A Desiderata for Broadband Networks in the Public Interest. Paper presented at the 35th Research Conference on Communication, Information and Internet Policy, Arlington, VA.

Powell, A. (2008). CWIRP Case Study Map: Fred E-Zone: Community Wireless Infrastructure Research Project.

Powell, A., \& Meinrath, S. D. (2008). Wireless Networking for Communities, Citizens, and the Public Interest: Global Perspectives. Journal of Community Informatics, 4(1).

Powell, A., \& Shade, L. R. (2006). Going Wi-Fi in Canada: Municipal, and Community Initiatives. Government Information Quarterly, 23(3-4), 381-403.

Puchol, M. (2006). The Real FON Statistics: Lies, Manipulation or Fantasy. Retrieved 31 May, 2008, from http://tech.am/2006/09/25/the-real-fon-statistics-\%E2\%80\%93-liesmanipulation-or-fantasy/. 
Reinhardt, A. (2006, 8 February). From Hot Spots to Fon Zones? Business Week Online.

Richtel, M. (2006). The Wi-Fi in Your Handset. New York Times.

Sandvig, C. (2004). An Initial Assessment of Cooperative Action in Wi-Fi Networking. Telecommunications Policy, 28(7/8), 579-602.

Savage, N. (2006, 27 February). Municipal Mesh Network. Technology Review.

Schneier, B. (2008, 10 January). Steal This Wi-Fi. Wired.

Schonfeld, E. (2008). FON Raises Another \$9.5 Million in C Round. Retrieved 31 May, 2008, from http://www.techcrunch.com/2008/04/10/fon-raises-another-95-million-in-c-round/.

Seybold, A. (2008). Muni-Wi-Fi Revisited. Retrieved 10 June, 2008, from http://www.andrewseybold.com/commentary.asp?ID=140.

Shah, R. C., \& Sandvig, C. (2005). Software Defaults as De Facto Regulation: The Case of Wireless APs. Paper presented at the 33rd Research Conference on Communication, Information and Internet Policy, Arlington, VA.

Sharwood, S. (2008, 12 February). Facebookers Net Wi-Fi. The Age, p. 1.

Simon, N. (2005). Interview with Martin Varsavsky. Retrieved 31 May, 2008, from http://blog.fon.com/en/archive/2005/11/.

Smith, D. (2008). Bt Community Forums: Precise Location of Hotspots? Retrieved 10 June, 2008, from http://www.beta.bt.com/bta/forums/thread.jspa?threadID=3196\&tstart=0.

Stanoevska-Slabeva, K., \& Hongisto, P. (2006). The Turku Approach to Create a Wireless Infrastructure. Paper presented at the Second European Conference on Mobile Government.

Stross, R. (2007, 4 February). Wireless Internet for All, without the Towers. New York Times, p. 3.

Tallberg, M. (2006). P2P-Based Roaming between Home WLAN Hotspots. Helsinki: Helsinki University of Technology.

Tanner, J. C. (2008, 4 March). Putting the 'Hot' in 'Hotspots'. America's Network.

Tapia, A., Maitland, C., \& Stone, M. (2006). Making IT Work for Municipalities: Building Municipal Wireless Networks. Government Information Quarterly, 23, 359-380.

Taylor, P. (2007, 9 August). Knit Your Own Network. Financial Times.

Thompson, N. A., Yin, Z., Luo, H., Zerfos, P., \& Singh, J. P. (2007). Authentication on the Edge: Distributed Authentication for a Global Open Wi-Fi Network, Proceedings of the 13th annual ACM international conference on mobile computing and networking. Montreal, Quebec, Canada: ACM.

Tropos Networks. (2007). Chaska.Net and Tropos Unwire Chaska, Minnesota. Retrieved 15 March, 2008, from http://web.archive.org/web/20070205031638/http://tropos.com/pdf/chaska casestudy. pdf.

Välimäki, J. (2006). Change of Business Models for Wireless Internet Access. Helsinki: Networking Laboratory, Helsinki University of Technology. 
Varsavsky, M. (2007a). Fiesta Fonera! Retrieved 31 May, 2008, from english.martinvarsavsky.net/fon/fiesta-fonera.html.

Varsavsky, M. (2007b). ISP Contracts and FON, Should You Worry? Retrieved 31 May, 2008, from http://english.martinvarsavsky.net/fon/isp-contracts-and-fon-should-youworry.html.

Varsavsky, M. (2008a). Bt FON Passes 100,000 Users. Retrieved 10 June, 2008, from http://english.martinvarsavsky.net/fon/bt-fon-passes-100000-users.html\#comments.

Varsavsky, M. (2008b). FON Latest Figures. Retrieved 31 May, 2008, from http://english.martinvarsavsky.net/general/fon-latest-figures.html.

Veldhuijzen Van Zanten, B. (2008). FON Raises \$9.5 Million: No More Free Hardware? Retrieved 31 May, 2008, from http://thenextweb.org/2008/04/12/fon-raises-95-million-no-morefree-hardware/.

Wong, M., \& Clement, A. (2007). Sharing Wireless Internet in Urban Neighbourhoods. In Steinfeld, C., Pentland, B. T., Ackerman, M. \& Contractor, N. (Eds.), Communities and Technologies 2007: Proceedings of the Third Communities and Technologies Conference. London: Springer-Verlag. 